\title{
A Clinicopathological Study of Olfactory Neuroblastoma
}

\section{Original Article}

\author{
Thripthi Rai K. ${ }^{1}$, Flora D. Lobo ${ }^{2}$, Vijendra Shenoy S. ${ }^{3}$, Sushmitha K. \\ ${ }^{1,3,4}$ Department of Otorhinolaryngology and Head and Neck Surgery, Kasturba Medical \\ College, Manipal Academy of Higher Education, Karnataka, India. ${ }^{2}$ Department of \\ Pathology, Kasturba Medical College, Mangalore, Manipal Academy of Higher Education, \\ Karnataka, India.
}

\begin{abstract}
Background: Olfactory neuroblastoma, also known as Esthesioneuroblastoma, is a malignant neoplasm of neuroectodermal origin. In view of its rarity, a clinicopathological study of esthesioneuroblastoma is presented.

Aim: Study Olfactory neuroblastoma cases diagnosed in the past ten years in patients attending Otorhinolaryngology outpatient.

Patients and Methods: A retrospective study was conducted at Kasturba Medical College, Mangalore from 2009-18. Patients who attended Otorhinolaryngology outpatient and proven histopathologically to have Olfactory neuroblastoma are included in the study with the exclusion criteria being metastasis of Neuroblastoma to Head and Neck. It is a timebound study and cases during the study period fulfilling the inclusion criteria are included.

Results: A total of six cases are taken up for the study. These include one female and five male patients. Epistaxis was the most common presenting complaint. All the patients had nasal mass and local spread was seen most commonly to paranasal sinuses, orbit and anterior cranial fossa. Level two lymph nodes were most commonly involved. Overall they were staged as Kadish $\mathrm{C}$ in three, $\mathrm{A}$ in two and $\mathrm{D}$ in one. Treatments included surgical resection and radiation therapy. Two patients presented with recurrence during follow-up out of which one was local and another nodal recurrence.

Conclusion: Although rare, any patient in the sixth decade presenting with epistaxis must be evaluated for Olfactory neuroblastoma. Better results are obtained with the combined modality of treatment. Also, the patients must be followedup for an extended period for the timely detection of recurrences.
\end{abstract}

Key Words: Epistaxis, kadish staging, nodal metastasis, olfactory neuroblastoma.

Received: 15 January 2020, Accepted: 7 April 2020

Corresponding Author: Thripthi Rai, MS, Assistant Professor, Department of Otorhinolaryngology and Head and Neck Surgery, Kasturba Medical College, Mangalore - 575001 Manipal Academy of Higher Education, Karnataka, India., Tel.: +91- 9164625754, E-mail: itsthripthi@gmail.com

ISSN: 2090-0740, November 2020 Vol.21, No.3

\section{INTRODUCTION}

Olfactory epithelium lines almost half of nasal cavity. This epithelium has olfactory receptor neurons with their cilia, sustentacular cells and basal cells. Olfactory receptor neurons are superficial in location allowing direct access to odorant materials. However, this exposes them to possible damage. The ultimate solution to this problem is replacing the neurons. This is achieved by presence of precursor stem cells among the basal cells. Due to their mitotically active nature, the basal cells are presumed to be the progenitor of the olfactory neuroblastoma ${ }^{[1]}$.

Esthesioneuroblastoma, esthesioneurocytoma, olfactory placode tumor, esthesioneuroma esthesioneuroepithelioma and are some older names for olfactory neuroblastoma.

First described in 1924 and with more than 1000 cases reported till date, olfactory neuroblastoma continues to be one of the rare intranasal tumours. Due to its rarity, there is hardly any consenses regarding staging and management.

The objective of this study is to collect data on all the Olfactory neuroblastoma cases diagnosed in our settings and aims to contribute to the scarce data we have on this rare entity.

\section{PATIENTS AND METHODS:}

A retrospective file review was done for all the patients diagnosed as having Olfactory neuroblastoma at Kasturba Medical College, Mangalore from 2009-2018. Patients with metastasis of neuroblastoma to head and neck were not included. Files were analysed for patient's demographic details, presenting complaints, examination findings, modified Kadish and Dulguerov staging, Hyams histologic grading, treatment and outcome on follow-up. In this study we have reviewed six cases of Olfactory neuroblastoma over ten year period and analysed the data. 


\section{RESULTS:}

The study was conducted in the Department of Otorhinolaryngology and Head and Neck surgery, Kasturba Medical College, Mangalore. There were six patients fulfilling our criteria for inclusion and were studied. The average age of presentation was 46 years, with male preponderance of $5: 1$. Epistaxis was the most common presenting complaint present in five patients $(83 \%)$. Other complaints were nasal obstruction, present in three patients $(50 \%)$ out of which one was bilateral. Headache was present in three patients $(50 \%)$, blurring of vision seen in two patient (33\%) and hyposmia and neck swelling seen in one patient $(17 \%)$. Average duration of symptoms was 8 months. All patients had reddish friable polypoidal mass in the nose. The extent was till middle meatus in two, inferior turbinate in three and filling entire nasal cavity in one patient. Palpable lymph nodes was found in only one case (17\%). Radiological study of nose and paranasal sinuses were done. CECT in two cases showed disease confined to nasal cavity. One case had involvement of nasopharynx, maxillary sinus, ethmoid sinus with destruction of bony nasal septum. Another case had involvement of all the sinuses with erosion of medial wall of orbit and orbital infiltration with extension to anterior cranial fossa. Last two cases in addition to above had infiltration into brain. Three patients were staged Kadish stage C, two stage A and one stage D. As per Dulguerov staging two cases were T1N0M0, one each were T2N1M0, T3N0M0, T4N0M0 and T4N1M0. Diagnosis of Olfactory neuroblastoma was made by histopathological and immunohistochemical evaluation of tissue from tumour mass in five and cytology of enlarged lymph node of neck in one case. Three cases were classified as Grade II and two as Grade IV as per Hyams criteria.

Treatments included surgical resection and radiation therapy. Two patients underwent only surgical resection and two underwent surgical resection with postoperative radiotherapy. One patient underwent radiotherapy alone and one didn't undergo any treatment and is lost to followup.

One patient who underwent only surgical resection came with recurrence after four years. Recurrence was seen in the nasal cavity limited till middle meatus. One of the patients who underwent combined modality of treatment had a recurrence in neck nodes three years after completion of initial treatment and underwent radiotherapy for the same. Patient who was treated with only radiotherapy, underwent Endoscopic sinus surgery after five months of initial treatment which revealed no residual disease.

Table 1: Clinical data of the olfactory neuroblastoma cases

\begin{tabular}{|c|c|c|c|c|c|c|c|c|c|c|}
\hline Sl no. & Age & Sex & $\begin{array}{l}\text { Presenting } \\
\text { complaints }\end{array}$ & Duration & $\begin{array}{c}\text { Kadish staging } \\
\text { with Morita's } \\
\text { modification }\end{array}$ & $\begin{array}{l}\text { Dulguerov } \\
\text { staging }\end{array}$ & $\begin{array}{l}\text { Hyam } \\
\text { grading }\end{array}$ & Treatment & $\begin{array}{c}\text { Follow- } \\
\text { up }\end{array}$ & Recurrence \\
\hline 1 & 43 & $\mathrm{~F}$ & Epistaxis & 36 months & A & T1N0M0 & II & Surgery & $\begin{array}{c}48 \\
\text { months }\end{array}$ & Local \\
\hline 2 & 56 & M & $\begin{array}{c}\text { Nasal } \\
\text { obstruction, } \\
\text { epistaxis, } \\
\text { headache }\end{array}$ & 2 months & A & T1N0M0 & II & NA & NA & NA \\
\hline 3 & 22 & $\mathrm{M}$ & $\begin{array}{l}\text { Epistaxis, } \\
\text { headache, } \\
\text { blurring } \\
\text { of vision }\end{array}$ & 1 month & $\mathrm{C}$ & T3N0M0 & II & Combined & $\begin{array}{c}48 \\
\text { months }\end{array}$ & $\begin{array}{l}\text { No } \\
\text { recurrence }\end{array}$ \\
\hline 4 & 33 & M & $\begin{array}{c}\text { Nasal } \\
\text { obstruction, } \\
\text { epistaxis, } \\
\text { hyposmia, } \\
\text { blurring } \\
\text { of vision }\end{array}$ & 6 months & $\mathrm{C}$ & T4N0M0 & IV & Combined & $\begin{array}{c}39 \\
\text { months }\end{array}$ & Nodal \\
\hline 5 & 53 & M & $\begin{array}{c}\text { Nasal } \\
\text { obstruction, } \\
\text { headache, } \\
\text { epistaxis }\end{array}$ & $\begin{array}{c}1.5 \\
\text { months }\end{array}$ & $\mathrm{C}$ & $\mathrm{T} 2 \mathrm{~N} 1 \mathrm{M} 0$ & IV & Surgery & NA & NA \\
\hline 6 & 72 & $\mathrm{M}$ & $\begin{array}{l}\text { Swelling in } \\
\text { the neck }\end{array}$ & 1 month & $\mathrm{D}$ & T4N1M0 & NA & Radiotherapy & 8 months & $\begin{array}{c}\text { No } \\
\text { recurrence }\end{array}$ \\
\hline
\end{tabular}




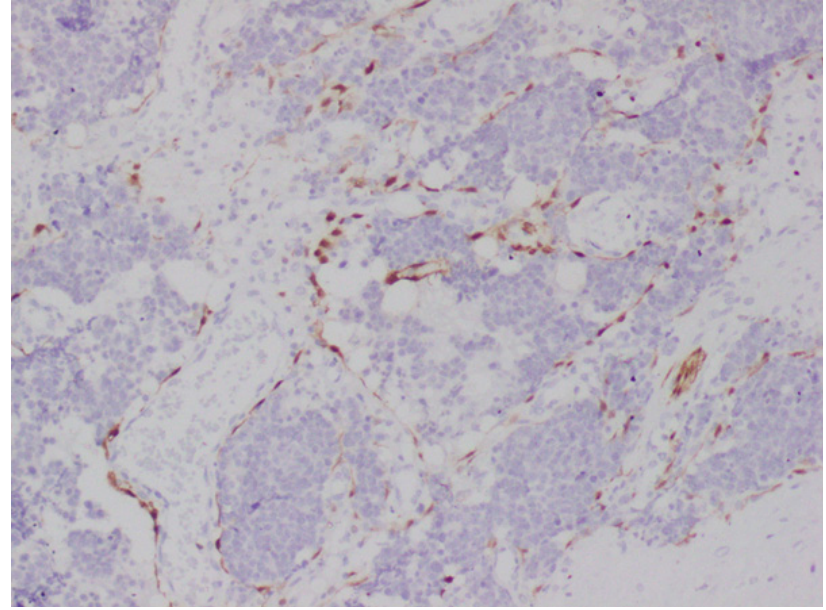

Fig. 1 : Histopathological Section Showing S100 Positivity

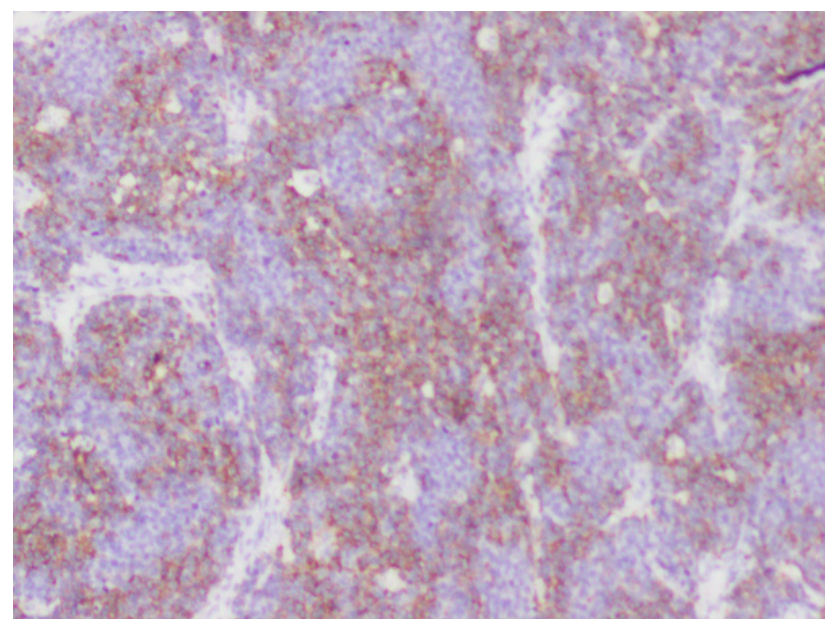

Fig. 2 : Histopathological Section Showing Tumour Cells Positive For Synaptophysin

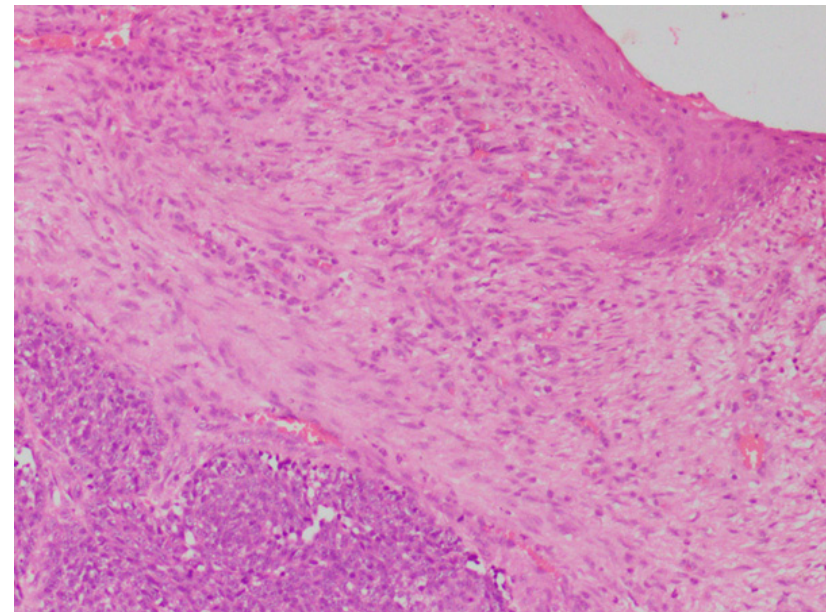

Fig. 3 : Nasal Lining Mucosa With Subepithelial Tumour

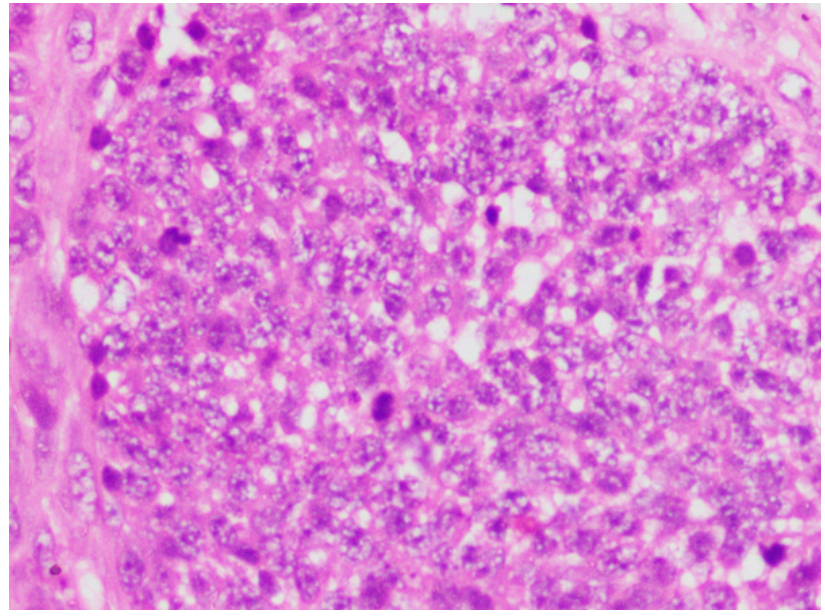

Fig. 4 : Atypical Mitosis Aggregates Of Tumour Cells

\section{DISCUSSION}

Olfactory neuroblastoma, which is a malignant neoplasm is neuroectodermal in origin. It was described first in 1924 by Berger et al in 'esthesioneuroepitheliome

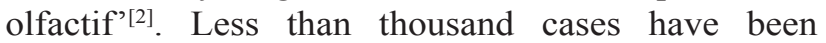
reported worldwide. Majority of cases are in the last few decades which could be due to the advanced diagnostic techniques and the easier availability of immunohistochemistry ${ }^{[3]}$.

It has bimodal incidence rate, with one peak at the second-third decade and the other peak at the sixthseventh decades. It is seen equally among males and females ${ }^{[4]}$. In our study only two patients conformed to this finding. Also there was higher male to female ratio.

The appearance of the first symptom and the diagnosis averages to around 6 months ${ }^{[5]}$. In our study it was eight months which is close.

Nasal obstruction and epistaxis are the most common symptoms according to literature, which is similar to our study ${ }^{[5]}$.

It is aggressive and invades locally as well as metastasises to regional and distant sites. Metastases mostly involve the cervical lymph nodes. Liver, bone, and lungs are the areas of distant metastasis ${ }^{[5,6,7]}$.

Only twenty nine percent have lymph node involvement on presentation ${ }^{[8]}$. In our study it was seventeen percent.

The most frequently involved lymph nodes were Level $\mathrm{II}^{[8]}$. Similar findings were seen in our study. 
Kadish staging system is based on the extension of Esthesioneuroblastoma. Stage A is confined to the nasal cavity, Stage B involves one or more paranasal sinuses and Stage $\mathrm{C}$ extends beyond these sites involving cribriform lamina, orbit, skull base or intracranial cavity ${ }^{[7]}$.

A fourth stage is included in modified Kadish staging system for patients with regional lymph node or distant metastase $^{[9]}$. In our study we had two patients in Kadish A, three in Kadish C and one in Kadish D.

The Dulguerov staging system is the TNM staging system with consideration of tumour extent including involvement of brain, cervical lymph node involvement and presence of distant metastasis ${ }^{[5]}$. In our study we had two patients with T1N0M0, one T2N1M0, one T3N0M0, one T4N0M0 and one T4N1M0.

Grossly, the tumour ranges from less than one $\mathrm{cm}$ to huge mass filling nasal cavity, paranasal sinuses, nasopharynx and intracranial regions. It is glistening, soft, polypoidal red-gray mass with gray-tan to pink cut surface and mimics other sinonasal tract primary malignancies. Characteristic microscopic features include lobular arrangement of primitive neuroblastoma cells, small round blue neoplastic cells, HomerWright pseudorosettes in upto $30 \%$ cases, FlexnerWintersteiner rosettes in 5\%, nuclear pleomorphism, mitosis and necrosis. Immunohistochemistry is positive for neuroendocrine markers, calretinin, S100 protein and sustentacular cells and negative for desmin, myogenin, CD45RB and CD99. Differential diagnosis include sinonasal undifferentiated carcinoma, neuroendocrine carcinoma, extranodal NK-/T-cell Lymphoma nasal type, NUT Midline carcinoma, rhabdomyosarcoma, malignant melanoma, PNET/ Ewing sarcoma, pituitary adenoma, extramedullary plasmacytoma and metastatic neuroblastoma ${ }^{[10]}$.

Grades 1-4 by Hyams system is based on presence of Histological parameters such as growth, mitotic activity, architecture, nuclear pleomorphism, necrosis, fibrillary stroma and nuclear rosette formation ${ }^{[11]}$. In our study three cases were of Grade II and two Grade IV.

In the study by M.C.Howell, majority of metastatic lymph nodes were moderately to highly FDG-avid ${ }^{[8]}$. This finding is similar to our study.

Endoscope can be used for purely endoscopic approach or endoscopic-assisted cranio-facial resections $^{[12]}$. In our study one patient underwent purely endoscopic resection whereas another patient underwent endoscopic combined with external resection. Several studies report show excellent results and lower rate of complications with purely endoscopic resection but in our study though Stage A Kadish, patient presented with recurrence within four years of surgery.

Craniofacial approaches which gives better disease-free survival has become the gold standard for treatment ${ }^{[13,14]}$. Best outcomes were with surgery and post-operative radiotherapy ${ }^{[15,16]}$. In our study, two patients, both Kadish $\mathrm{C}$ underwent craniofacial resection followed by radiation therapy. While one patient is disease free almost four years after treatment, second one developed a lymphnode metastasis after three years.

Radiation or surgery when used alone was found to have worst results including higher local recurrence and distal metastasis ${ }^{[17]}$. In our study, the patient with only surgical treatment developed recurrence after four years. Patient who underwent radiation only has no recurrence six months after completion.

\section{CONCLUSION}

In conclusion, Olfactory neuroblastoma is a rare tumour with highest incidence in sixth decade of life and higher incidence in males. Every patient presenting with epistaxis and nasal obstruction must be evaluated for Olfactory neuroblastoma. Immunohistochemical stains are a must for accurate diagnosis. Local spread is mainly to the paranasal sinuses, orbit and anterior cranial fossa. Regional metastasis is to level two lymph nodes which have strong FDG avidity making PET$\mathrm{CT}$ an excellent tool for diagnosis and post- treatment surveillance. Single modality of treatment even in early stages has high chances of local recurrence. Combined modality provides good results even in advanced stages provided there is no involvement of brain. An extended follow-up period is recommended in Olfactory neuroblastoma patients.

\section{CONFLICT OF INTEREST}

There are no conflicts of interest.

\section{REFERENCES}

1. Ashraf M, Ashraf S, Jabr IA. Esthesioneuroblastoma - A Clinicopathological Study. Int Arch BioMed Clin Res. 2017; 3(1): 54-7.

2. L. Berger, R. Luc and D. Richard, "L'esthesioneuroepitheliome Olfactif," Bulletin de l'Association Fran?aise pour l'étude du Cancer. 1924; 13: 410-21.

3. Shaffy, Arnav Kr. Roychoudhury, Navleen Kaur. Esthesioneuroblastoma - an unusual case report. International Journal of Contemporary Medical Research. 2016; 3(11): 3137-9. 
4. Tural D, Yildiz O, Selcukbiricik F, Ozturk MA, Keles $\mathrm{Y}, \mathrm{Oz} \mathrm{B}$ et al. Olfactory neuroblastomas: an experience of 24 years. ISRN Oncol. 2011; 2011: 451086.

5. Dulguerov P, Calcaterra T. Esthesioneuroblastoma: the UCLA experience 1970-1990. Laryngoscope. 1992 Aug; 102(8): 843-9.

6. Broich G, Pagliari A, Ottaviani F. Esthesioneuroblastoma: a general review of the cases published since the discovery of the tumour in 1924. Anticancer Res. 1997 Jul-Aug; 17(4A): 2683-706.

7. Kadish S, Goodman M, Wang CC. Olfactory neuroblastoma. A clinical analysis of 17 cases. Cancer. 1976 Mar; 37(3): 1571-6.

8. Howell MC, Branstetter $\mathrm{BF} 4^{\text {th }}$, Snyderman $\mathrm{CH}$. Patterns of regional spread for esthesioneuroblastoma. AJNR Am J Neuroradiol. 2011 May; 32(5): 929-33.

9. Morita A, Ebersold MJ, Olsen KD, Foote RL, Lewis JE, Quast LM. Esthesioneuroblastoma: prognosis and management. Neurosurgery. 1993 May; 32(5): 706-14.

10. Lester D.R.Thompson, Bruce M.Wenig. "Olfactory neuroblastoma- Tumours of Nose and Paranasal sinus". Diagnostic Pathology Head and Neck. Second Edition. Elsevier publications; 2016. 124-33.

11. V.J.Hyams. "Olfactory neuroblastoma": V.J.Hyams, J.G.Baksakis, L.Michels, Eds. Tumours of the upper
Respiratory tract and Ear. Washington, DC, USA: Armed Forces Institute of Pathology; 1998. 240-248.

12. Palejwala SK, Sharma S, Le CH, Chang E, Lemole M. Complications of Advanced Kadish Stage Esthesioneuroblastoma: Single Institution Experience and Literature Review. Cureus. 2017 May 12; 9(5): e1245.

13. Resto VA, Eisele DW, Forastiere A, Zahurak M, Lee DJ, Westra WH. Esthesioneuroblastoma: the Johns Hopkins experience. Head Neck. 2000 Sep; 22(6): 550-8.

14. Zafereo ME, Fakhri S, Prayson R, Batra PS, Lee J, Lanza DC et al. Esthesioneuroblastoma: 25-year experience at a single institution. Otolaryngol Head Neck Surg. 2008 Apr; 138(4): 452-8.

15. Dulguerov P, Allal AS, Calcaterra TC. Esthesioneuroblastoma: a meta-analysis and review. Lancet Oncol. 2001 Nov; 2(11): 683-90.

16. Loy AH, Reibel JF, Read PW, Thomas CY, Newman SA, Jane JA et al. Esthesioneuroblastoma: continued follow-up of a single institution's experience. Arch Otolaryngol Head Neck Surg. 2006 Feb; 132(2): 134-8.

17. Gruber G, Laedrach K, Baumert B, Caversaccio M, Raveh J, Greiner R. Esthesioneuroblastoma: irradiation alone and surgery alone are not enough. Int J Radiat Oncol Biol Phys. 2002 Oct 1; 54(2): 486-91. 